\title{
Effect of Cornus mas fruit flavonoids on memory retention, level of plasma glucose and lipids in an intra- cerebroventricular streptozotocin-induced experimental Alzheimer's disease model in Wistar rats
}

\author{
Niloufar Darbandi*, Azam Hashemi, Mitra Noori, Hamid Reza Momeni \\ Department of Biology, Faculty of Science, University of Arak, Arak 38156-8-8349, Iran \\ ${ }^{*}$ Corresponding author, E-mail: N-Darbandi@araku.ac.ir
}

\begin{abstract}
Poor nutrition, poor mobility, obesity and ageing increase the possibility of neuronal disorder and Alzheimer's disease. This study examined effect of Cornus mas flavonoids on memory retention and the level of plasma glucose and lipids in an intra-cerebroventricular streptozotocin-induced experimental Alzheimer's disease model in Wistar rats. Intracerebroventricular administration of streptozotocine (3 mg kg-1) was performed and the animals memory were evaluated through passive avoidance tasks. Five groups (saline-saline control, streptozotocine-saline, and streptozotocine with different flavonoid doses [5, 10,20 mg kg-1]) were examined. Animals received different doses of C. mas flavonoids or saline for three weeks starting one day before surgery. Rat weight was measured at the beginning of each week. Injection of streptozotocine significantly reduced memory retention, compared to the control group. Flavonoid treatment increased memory retention in a dose-dependent manner, and triglyceride and glucose concentration decreased memory retention. At the same time, high-density lipoprotein concentration increased without any effect on low-density lipoprotein concentration. The dose of $10 \mathrm{mg} \mathrm{kg}^{-1}$ decreased rat weight significantly. Our findings show that $C$. mas flavonoids can optimize cognitive deficits caused by injections of streptozotocine and also have a few positive effects on reducing the risk factors in the serum.
\end{abstract}

Key words: Cornus mas flavonoids, plasma glucose, streptozotocine, memory, serum lipids.

Abbreviations: AD, Alzheimer's disease; HDL, high-density lipoproteins; ICV, intracerebroventricular; LDL, low-density lipoproteins; STZ, streptozotocine.

\section{Introduction}

Alzheimer's disease $(\mathrm{AD})$ is a progressive degenerative disease causing memory disorder, decreasing cognitive function and ability, and resulting in behavioral changes (Hoseini, Nobakht 2012). The origin of the disease is unknown but it ultimately shrinks the brain, destroys brain cells, and causes aging plaques and neurofibrillary tangles in brain cells (Haroutunian et al. 2009). Recent studies suggest that besides ageing as a main risk factor for $\mathrm{AD}$, life style and nutritional behaviors play a critical role in the onset of dementia (Iosa et al. 2014). Poor nutrition, poor mobility and obesity in the recent decades have led to an increase of neuronal disorder and metabolic syndrome. Some factors such as hyperglycemia, hypertension, high plasma concentration of triglycerides and low concentration of high-density lipoprotein (HDL) cholesterol, insulin resistance, glucose intolerance and oxidative stress have all been reported in metabolic syndrome (Razay et al. 2007). Some of these risk factors have a key role in progressive cognitive disorder and Alzheimer's disease (Vanhanen et al. 2006). Numerous studies suggest that oxidative stress including lipid peroxidation, protein oxidation and DNA oxidation is an early feature in the pathogenesis of neuronal damage in AD (Zhi-you, Yong 2007).

Some studies have indicated that the flavonoids are able to cross the blood-brain barrier (Williamson, Clifford 2010) and have a positive effect on the reduction of neuronal damage disorders in the brain such as in the case of $\mathrm{AD}$ (Harborne, Williams 2000). Flavonoids can scavenge free radicals with several mechanisms in order to prevent the occurrence of oxidative stress. These mechanisms include direct inhibition of free radicals, and then oxididation of flavonoids. In other methods, flavonoids absorb free radicals and inhibit their oxidation (Choi et al. 2003). These compounds use many different mechanisms to reduce blood parameters that can reduce the inflammatory cytokines and production of $\beta$-amyloid and increase the sensitivity of cells to insulin, hence effective in preventing the rapid advancement of Alzheimer's disease (ShukittHale, Lau 2008; Sun, Hongpaisan 2009; Rendeiro, Guerreiro 2012).

Cornus mas L. (cornelian cherry) contains high levels of antioxidants and anthocyanins and has been used for 
gastrointestinal and excretory disorders for many years in traditional medicine. Some studies have shown that C. mas may improve kidney and liver functions, and have protective effects such as antidiabetic, anti-allergic, antihistamine, antibacterial, and antimalarial properties (Alavian et al. 2014; Somi et al. 2014). Oral administration of C. mas fruits extract to rats for 14 to 16 days provided significant hepatoprotection by a decreased serum level of enzymes, total serum protein, albumin and liver lipid peroxidation concentration as well as liver antioxidant enzyme activity. Also, treatment with C. mas fruit extract treatment ameliorated myocardial injury and enhanced the antioxidant defense against $\mathrm{CCl}_{4}$-induced cardiotoxicity in rats and exhibited cardioprotective properties (Eshaghi et al. 2012). Infusion of C. mas fruit extract had no effect on serum ghrelin and corticosterone levels in a rat model, although it may have considerable effect on glycemic status (Narimani-Rad et al. 2013). In another study the effect of 21 days of $C$. mas hydro-methanolic extract administration on rat hematological and biochemical parameters was investigated (Narimani-Rad et al. 2014).

Besides the potential use of C. mas flavonoids in reducing oxidative stress and inflammatory cytokine levels and in increasing cells' sensitivity to insulin, the flavanoids may also reduce glucose levels, remove blood disorders and reduce body weight. The present study examined the possible effects of $C$. mas flavonoids on memory retention and level of plasma glucose and lipids in an intra-cerebroventricular streptozotocine (STZ) induced experimental AD model in Wistar rats.

\section{Materials and methods}

\section{Preparation of C. mas fruit flavonoids}

Mature fresh fruit of Cornelia Cherry C. mas (Cornaceae) was collected locally. It was identified and authenticated in accordance with the descriptions provided (Mozaffarian 2005). Fruits were dried in shade for a week after seed separation. Extraction of the prepared fruit material was done using $70 \%$ ethanol. Then flavonoids in the aqueousethanolic extract were detected, isolated and identified by two-dimensional paper and thin layer chromatography according to the available methods (Markham 1982). The pure fruit flavonid extract was kept in dark vials and stored in cool conditions until use.

\section{Animals}

Male Wistar rats (Pasteur Institute; Tehran, Iran) weighing 220 to $250 \mathrm{~g}$ at the time of surgery were used. The animals were kept in an animal house under a $12 / 12 \mathrm{~h}$ light/dark cycle and controlled $\left(22 \pm 2{ }^{\circ} \mathrm{C}\right)$ temperature. The rats had free access to food and water. All animals were allowed to adapt to the laboratory conditions for at least 1 week before the surgery and were handled for 5 min per day during this adaptation period. Each animal was used once only. Eight animals were used in each experimental group and all procedures for the treatment of the animals were approved by the Research and Ethics Committee of the Biology School, the University of Arak and were done in accordance with the National Institutes of Health Guide for Care and Use of Laboratory Animals (Publication no. 8023, revised 1996).

\section{Surgical and infusion procedures}

All surgical procedures were conducted under ketaminexylazine $\left(50 \mathrm{mg} \mathrm{kg}{ }^{-1}\right.$ ketamine and $5 \mathrm{mg} \mathrm{kg}^{-1}$ xylazine) anesthesia (Roghani et al. 2006). Stainless steel, 22-gauge guide cannulas were implanted (bilaterally) $1 \mathrm{~mm}$ above the intended site of injection according to the Paxinos and Watson (1988) atlas. Stereotaxic coordinates for lateral ventricle were incisor bar $(-3.3 \mathrm{~mm}), 0.8 \mathrm{~mm}$ posterior to the bregma, $\pm 1.4 \mathrm{~mm}$ lateral to the sagital suture and 3.4 $\mathrm{mm}$ from the top of the skull. Cannulas were secured by jewelers' screws with dental acrylic. For drug infusion, the animals were gently restrained by hand and injected by 27 -gauge injection needles ( $1 \mathrm{~mm}$ below the tip of the guide cannulas). Each injection unit was injected by polyethylene tubing attached to a $25 \mu \mathrm{L}$ Hamilton syringe. The left and right ventricles were infused with a $10 \mu \mathrm{L}$ solution on each side ( $20 \mu \mathrm{L}$ per rat) over 2 to $3 \mathrm{~min}$. The injection needles were left in place for an additional $60 \mathrm{~s}$ to allow diffusion and then the styles were reinserted into the guide cannulas.

\section{Passive avoidance apparatus}

The learning box consisted of two compartments: one lit (white compartment, $20 \times 20 \times 30 \mathrm{~cm}$ ) and the other dark (black compartment, $20 \times 20 \times 30 \mathrm{~cm}$ ). A guillotine door opening $(7 \times 9 \mathrm{~cm})$ was made on the floor in the center of the partition between the two compartments. Stainless steel graids $(0.4 \mathrm{~mm}$ in diameter) were placed at $1-\mathrm{cm}$ intervals (distance between the centers of grades) on the floor of the dark compartment to produce a foot shock. Intermittent electric shocks $(1 \mathrm{~Hz}, 3 \mathrm{~s}, 0.2 \mathrm{~mA})$ were delivered to the grid floor of the dark compartment by an insulated stimulator.

\section{Training}

The method for training was based on that employed in our previous studies (Ejaz Ahmed et al. 2013). All animals were allowed to habituate in the experimental room for at least $30 \mathrm{~min}$ prior to the experiments. Then, each animal was gently placed in the brightly lit compartment of the apparatus; after five seconds the guillotine door was opened and the animal was allowed to enter the dark compartment. The latency with which the animal crossed into the compartment was recorded. Animals that waited for more than $100 \mathrm{~s}$ to cross to the dark compartment were eliminated from the experiments. Once the animal crossed with all four paws into the next compartment, the guillotine door was closed and the rat was placed in its cage (habituation trail). The acquisition trail was carried out 30 
min after the habituation trail. The animal was placed in the light compartment and $5 \mathrm{~s}$ later the guillotine door was opened; as soon as the animal crossed to the dark (shock) compartment the door was closed and a foot shock $(1 \mathrm{~Hz}$, $10.2 \mathrm{~mA}$ and $3 \mathrm{~s}$ ) was immediately delivered to the grid floor of the dark room. After $20 \mathrm{~s}$, the rat was removed from the apparatus and placed temporarily in its cage. Two minutes later, the procedure was repeated. The rat received a foot shock each time it re-entered the dark part and had placed all four paws in the compartment. The training was terminated once the rat remained in the light compartment for 120 consecutive seconds. The numbers of trails (entries into the dark chamber) were recorded. All of the animals were taught with a maximum of three trails.

\section{Retention test}

Twenty-four hours after the training, a retention test was performed to determine long-term memory. Each animal was placed in the light compartment for $20 \mathrm{~s}$, the door was opened and the step through latency was measured for entering into the dark compartment. The test session ended when the animal entered the dark compartment or remained in the light compartment for $300 \mathrm{~s}$ (criterion for retention). During these sessions, no electric shock was applied (Roghani et al. 2007).

\section{Drugs}

The drugs used in the study were streptozotocine (SigmaAldrich, USA) and C. mas fruit flavonoids (5, 10, $20 \mathrm{mg}$ $\left.\mathrm{kg}^{-1}\right)$. The drugs were dissolved in sterile $0.9 \%$ saline just before the experiment. Streptozotocine was administered into the lateral ventricle and $C$. mas fruit flavonoid or saline were injected intraperitoneally (i.p.).

\section{Experimental procedure}

Eight animals were chosen for each experimental group. The therapeutic period was 21 days for all of the rats. They were treated on the first and the third day with STZ $(3 \mathrm{mg}$ $\mathrm{kg}^{-1}$; i.c.v.; bilateral with $10 \mu \mathrm{L}$ volume in either side) or saline as a placebo (i.c.v.; bilateral with $10 \mu \mathrm{L}$ volume in either side). All of the animals receiving STZ or saline were infused for 21 days with different doses of flavonoids $(5,10$, $20 \mathrm{mg} \mathrm{kg}^{-1}$ i.p.) or saline $\left(1 \mathrm{~mL} \mathrm{~kg}^{-1}\right.$ i.p.) starting one day before the surgery. On day 22 , without any treatment, the rats were trained in a step-through apparatus. Twenty-four hours later, a retention test was performed to determine the rate of long-term memory. All experiments were performed in the morning between 9:00 and 12:00.

Body weight of rats was measured at the beginning of each week. After the behavioral test and a subsequent period of $14 \mathrm{~h}$ without food, animals were killed one at a time. Blood was obtained through the heart right ventricle and concentrations in blood of glucose, triglyceride, the LDL-cholesterol and the HDL-cholesterol were determined with enzymatic and photometric methods.
In the memory retrieval experiment, five groups of animals were treated on the first and third day by STZ (3 $\mathrm{mg} \mathrm{kg}^{-1}$; i.c.v.; bilateral with $10 \mu \mathrm{L}$ volume in either side) or saline as a placebo (i.c.v.; bilateral with $10 \mu \mathrm{L}$ volume in either side). All of the animals were infused with saline (1 $\mathrm{ml} \mathrm{kg}{ }^{-1}$ i.p.) or different doses of flavonoids $(5,10,20 \mathrm{mg}$ $\mathrm{kg}^{-1}$ i.p.) for 21 days. On day 22 , without any treatment, the rats were trained in a step-through apparatus. Twenty-four hours later, a retention test was performed to determine the rate of the long-term memory (Fig. 1).

\section{Verification of cannula placement}

At the end of the experiment, to assess the validity and accuracy of the coordinates of the surgical site and the injection, $1 \mu \mathrm{L}$ of $1 \%$ aqueous solution of methylene blue was bilaterally injected. Animal brain was removed from the skull and was fixed in $10 \%$ formalin solution for 10 days. Sections were examined to determine the location of the cannulas aimed for the lateral ventricle. The cannula placements were verified using the atlas of Paxinos and Watson (Paxinos, Watson 1988). Data from the animals with the injection sites located outside the lateral ventricle (less than 5\%) were not used in the analysis.

\section{Statistical analysis}

For all experiments, the avoidance test data and the data related to the blood parameters were analyzed using SPSS software and unilateral variance analysis (one-way ANOVA) and the Tukey test. The weight data were also analyzed by SPSS software through repeated measures analysis of variance.

Differences at $P<0.05$ were regarded as significant. All results are shown as mean \pm standard deviation from the mean. Charts were drawn using Sigma Plot software.

\section{Results}

Flavonoid concentration in C. mas fruit was $32 \mathrm{~g} \mathrm{~kg}^{-1}$ on a dry mass basis, consisting of flavonoid sulphates and $\mathrm{C}$ and C-O glycosides of flavones. Chrysin, isorhamnetin, kaempferol, myercetin, quercetin and rutin were identified as the main constituents.

Rat receiving intraventricular injections of streptozotocin $\left(3 \mathrm{mg} \mathrm{kg}^{-1}\right)$ in the first and the third day of the surgery had a significant delay in entering the dark room in comparison to the control group (Fig. 1). Consequently, STZ reduced memory creating a delay in memory response in $24 \mathrm{~h}$. The administration of different doses of C. mas flavonoids (5,10 and $20 \mathrm{mg} \mathrm{kg}^{-1}$ i.p.), 21 days before the training and injection of STZ in the first and third day of surgery improved memory, compared to that of the STZ group. Treatment with different doses of C. mas flavonoids significantly reduced the period of time before entering in a dark room. The maximum effect was observed with $10 \mathrm{mg}$ $\mathrm{kg}^{-1}$ of flavonoids $\left(F_{4,32}=63.576, p<0.001\right)$. 


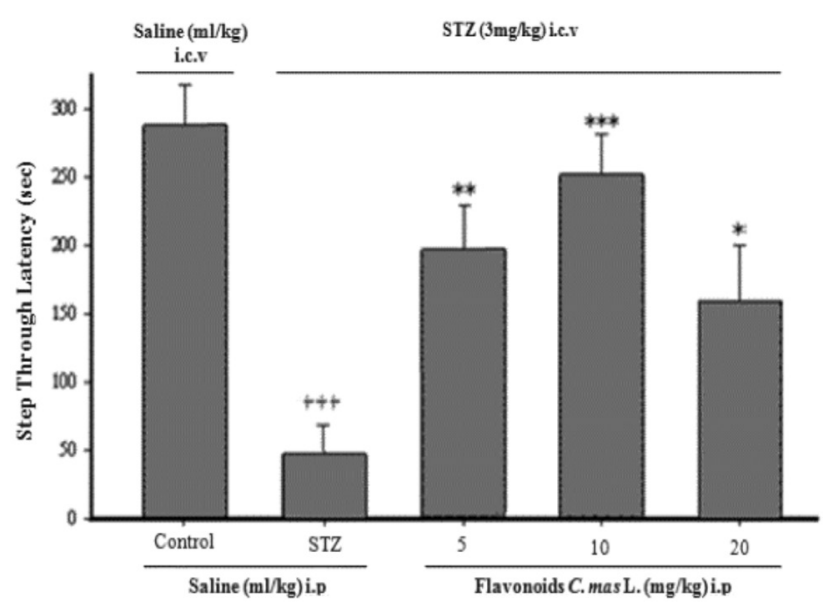

Fig. 1. Streptozotocin induced amnesia in rats with Alzheimer's disease compared to the control group. Results are expressed as mean \pm SD from eight animals. ${ }^{++} p<0.001$ compared to control. ${ }^{\star} p<0.05,{ }^{* *} p<0.01,{ }^{* *} p<0.001$ is compared to STZ group.

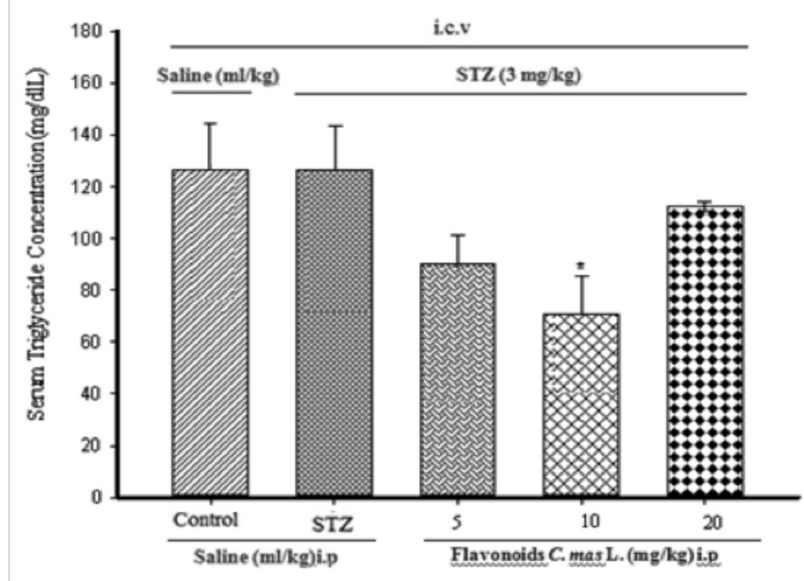

Fig. 3. The effect of intraperitoneal injections of different doses $C$. mas flavonoids on triglycerides concentration in the serum. The results are expressed as mean \pm SD from eight animals. ${ }^{*} p<0.05$ compared with control group.

There were no significant differences in the serum glucose concentrations between the control and STZ group (Fig. 2). Also, the comparison of the serum glucose levels among the groups treated with different doses of C. mas flavonoids fruit along with STZ showed that the glucose concentration of the serum was significantly lower only in animals receiving the dose of $10 \mathrm{mg} \mathrm{kg}^{-1}$, in comparison to control and STZ groups $\left(F_{4,16}=6.659, p<0.05\right)$.

Similarly, concentration of triglycerides of the serum between the control and STZ groups did not differ significantly. Intraperitoneal administration of different doses of C. mas flavonoids reduced the triglyceride concentration of the serum. The triglyceride concentration in blood of animals receiving a dose of $10 \mathrm{mg} \mathrm{kg}^{-1}$ was significantly lower in comparison to control and STZ groups $\left(F_{4,16}=3.775, p<0.05\right)$ (Fig. 3 ).

Administration of different doses of $C$. mas flavo-

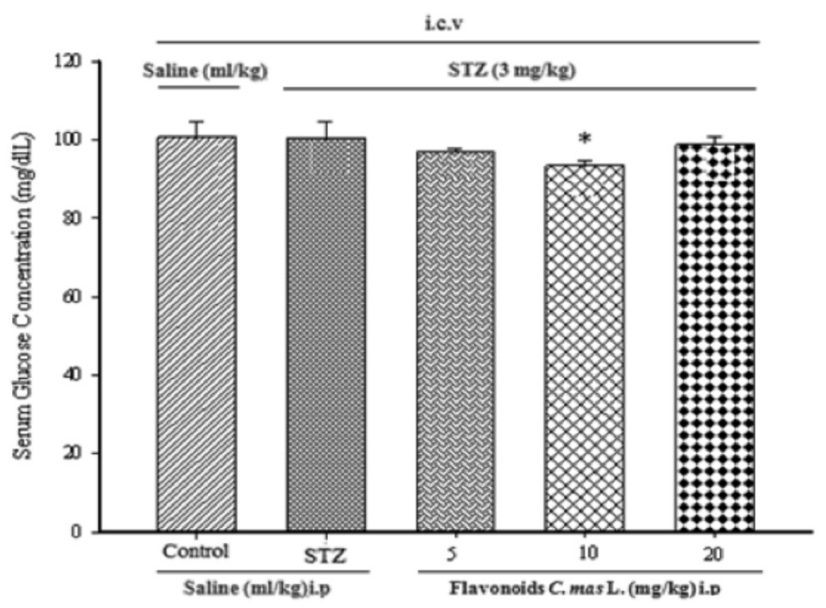

Fig. 2. The effect of intraperitoneal injections of different doses C. mas flavonoids on glucose concentration in the serum. The results are expressed as mean \pm SD from eight animals. ${ }^{\star} p<0.05$ compared with control group.

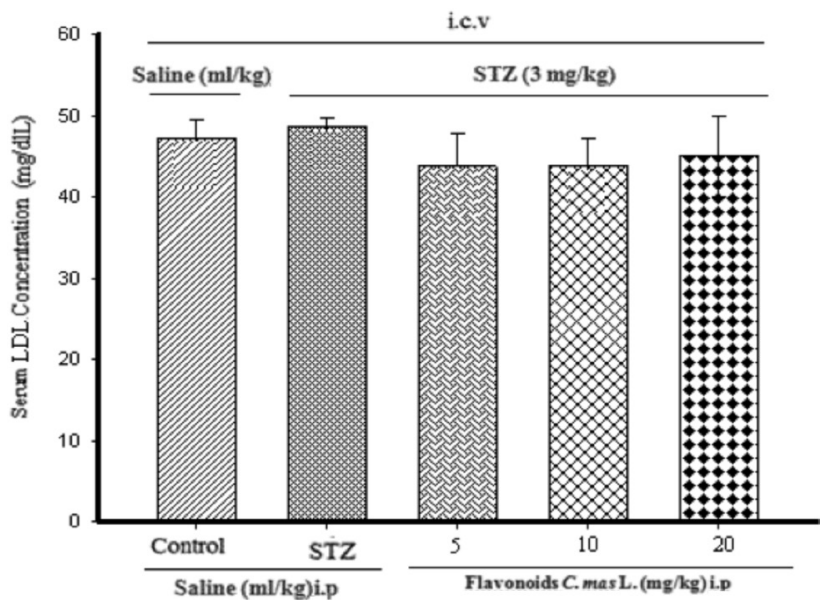

Fig. 4. The effect of intraperitoneal injections of different doses C. mas flavonoids on LDL concentration in the serum. The results were expressed as mean \pm SD from eight animals.

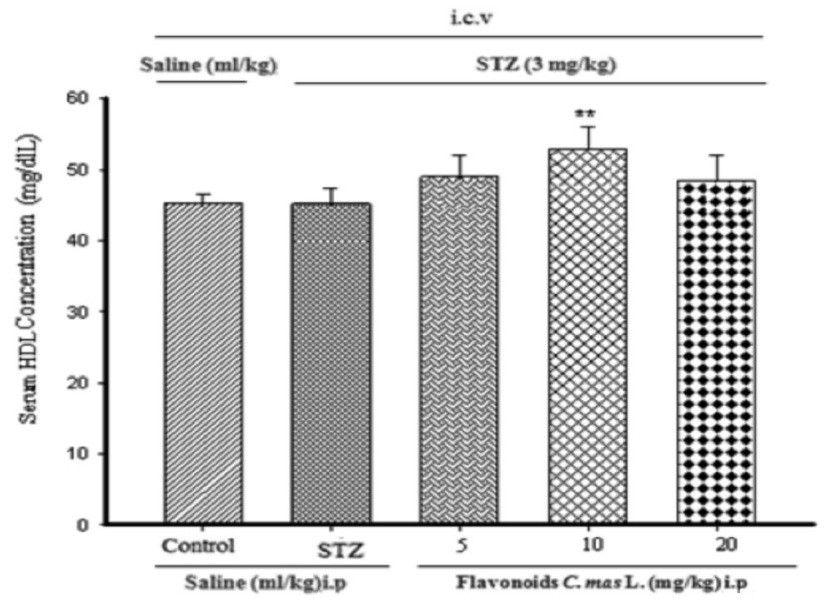

Fig. 5. The effect of intraperitoneal injections of different doses C. mas flavonoids on HDL concentration in the serum. The results are expressed as mean \pm SD from eight animals. ${ }^{* *} p<0.01$ compared with control group. 
Table 1. Comparison of mean \pm standard errors of weight in grams during the weeks of treatment among a control group, STZ group, and groups treated with $C$. mas flavonoids along with STZ. ${ }^{\star}$, significant reduction in body weight of rats compared to the control and the STZ groups $(p<0.05)$

\begin{tabular}{|c|c|c|c|c|}
\hline \multirow[t]{2}{*}{ Treatment } & \multicolumn{4}{|c|}{ Time (weeks) } \\
\hline & 1 & 2 & 3 & 4 \\
\hline Control & 246.620 .8 & 267.819 .8 & 286.620 .0 & 298.219 .0 \\
\hline STZ & 248.016 .9 & 255.134 .3 & 313.56 .8 & 293.518 .2 \\
\hline $\mathrm{STZ}$ + flavonoids $5 \mathrm{mg} \mathrm{kg}^{-1}$ & 250.618 .9 & 233.936 .2 & 230.732 .7 & 211.028 .3 \\
\hline $\mathrm{STZ}$ + flavonoids $10 \mathrm{mg} \mathrm{kg}^{-1}$ & 249.121 .9 & 242.420 .5 & 231.111 .2 & $210.322 .1^{*}$ \\
\hline STZ + flavonoids $20 \mathrm{mg} \mathrm{kg}^{-1}$ & 230.89 .6 & 212.924 .0 & 214.617 .4 & 280.316 .6 \\
\hline
\end{tabular}

noids did not result in a significant reduction in LDL concentration of the serum in any of the group, as compared to control and STZ groups $\left(F_{4,16}=1.627, p>0.05\right)$ (Fig. 4). Similarly, no significant difference in the concentration of HDL of the serum between control and STZ groups was found. However, administration of different doses of C. mas flavonoids caused increased HDL concentration in the serum. The HDL concentration was significantly higher in the group that received $10 \mathrm{mg} \mathrm{kg}^{-1}$ of flavonoids, in comparison to control and the STZ groups $([\mathrm{F}(4,16)=$ 4.702, $\mathrm{P}<0.01]$ ) (Fig. 5).

Comparison of body weights of the groups treated with STZ and different doses of fruit flavonoids with those of STZ and control groups showed that the reduction of body weight was significantly diverted by flavonoids only at the dose of $10 \mathrm{mg} \mathrm{kg}^{-1}\left(F_{5,44}=16.068, p<0.05\right.$; Table 1$)$.

\section{Discussion}

Based on the results obtained from this study, the intraventricular injection of STZ $\left(3 \mathrm{mg} \mathrm{kg}^{-1}\right)$ at the volume of $10 \mu \mathrm{L}$ in each ventricle on the first and third day after surgery caused loss of memory after 21 days. Many previous studies confirm our findings (Mehla et al. 2013; Rai et al. 2013). Intracerebroventricular injection of STZ at this dose led to significant defects in the memory of the animals (Rai et al. 2013). It appears that this drug can lead to insulin resistance in brain cells which reduces the expression of insulin and therefore increases glucose concentration in the brain, and reduces the energy available to the cells (Roghani et al. 2007). It was recently shown that intraventricular injection of STZ in rats, by increasing glucose in the brain, is able to increase conversion of amyloid precursor protein to $\beta$-amyloid and intensifies the inflammatory process. This combination reduces insulin expression in the hippocampus and cerebral cortex (Chu, Qian 2005) and also causes a reduction in protein kinase $C$ activity and oxidative stress and increases the production of reactive oxygen species and reactive nitrogen species, and the ratio of $\mathrm{Bax} / \mathrm{Bcl} 2$ in the hippocampus (Kundurovic et al. 2009). In such circumstances, the amount of caspase- 3 in the cerebral cortex and hippocampus increases and the neurons undergo apoptosis (Ejaz et al. 2013). Research also suggests that beta-amyloid increases the production of free radicals and lipid oxidation in BCL2 nerve cells, which leads to cell death (Heo et al. 2004).

In the present study, treatment of STZ memoryimpaired animals with C. mas fruit flavonoids significantly improved memory retention. Some reports have confirmed the present findings (Gould et al. 1999). Flavonoids have a potential to improve memory by protecting neurons against damages caused by neurotoxins and cause inflammation of the nervous system (Shors et al. 2002). These compounds react with neural signaling cascades, which are important in the brain, and lead to greater cell survival by apoptosis inhibition and improving synaptic plasticity of the nervous system (Drapeau et al. 2003). Flavonoids regulate the transcription factors and affect the expression of genes involved in cell survival in some particular areas in Denta gyrus and CA3 regions of the hippocampus, by affecting lipid kinase via the PI3/Akt and MAP kinase pathway; they also create long-term potentiation by improving neuronal connections (Gould et al. 1999; Shors et al. 2002). Flavonoids also cause changes in cerebral blood flow, leading to angiogenesis and neurogenesis, particularly in the hippocampus, and morphology changes in the brain (Jeremy 2007). Flavonoids play an important role in the upregulation of the brain-derived neurotrophic factor, which is a protein that facilitates survival of nerve cells and plays a key role in the growth, differentiation and evolution of cells (Jeremy 2009).

In the present study, which was conducted in a three-week period, it was observed that there was a significant decrease in the concentration of serum glucose in rats treated with $10 \mathrm{mg} \mathrm{kg}^{-1}$ of C. mas fruit flavonoids. Although research on the effects of polyphenolic compounds on blood glucose levels has produced conflicting results, several studies are in agreement with these findings. The use of polyphenol rutin significantly reduced fasting blood glucose and glycosylated hemoglobin levels in diabetic rats after 45 days (Kamalakkannan, Prince 2006). Administration of flavonoid naringenin (10 $\mathrm{mg} \mathrm{kg}^{-1}$ i.p.) for five weeks significantly decreased plasma glucose concentration in rats (Fallahi et al. 2012). Epigallocatechin-3 gallate, by down-regulation of the expression of some enzymes, reduces blood glucose levels (Ebrahimi-Mamaghani et al. 2009). Kaempferol 
prepared from mimosa leaves $\left(200 \mathrm{mg} \mathrm{kg}^{-1}\right.$ ) reduces blood sugar in alloxan-induced diabetic rats and causes a drop in glucose concentration in healthy rats blood one hour after oral administration (De Sousa et al. 2004). In other studies, it has been noted that flavonoid aglycones promote uptake of glucose by facilitating diffusion (Ruderman et al. 1998), while glycosidic flavonoids inhibit glucose absorption via active transport (Tanaka et al. 2002). Studies have shown that flavonoids increase the amount of GLUT4 and insulin receptors on the cell surface and increase glucose uptake by cells. On the other hand, these compounds have an effect on the small intestine and reduce the amount of GLUT2 glucose carriers. This causes a reduction of maltase enzyme and also the uptake of glucose (Szkudelski, Szkudelski 2011). Antioxidant treatment increases the $\beta$-cell mass and maintains insulin content and amount of mRNA (Kaneto et al. 1999). Adiponectin modulates glucose and lipid metabolism. Flavonoids improve adiponectin expression, which improves insulin sensitivity via enhanced PPAR $\gamma$ function and down-regulated TNF- $\alpha$ and IL-6 (Wein et al. 2010; Lei et al. 2011). PPARa has a major role in the regulation of energy homeostasis, increases fatty acid oxidation, stimulates heme synthesis and cholesterol catabolism and attenuates inflammatory responses. PPAR $\gamma$ variants are associated with insulin resistance and glucose homeostasis and adipogenesis (Michalik et al. 2006).

According to the results of this study, treatment with C. mas fruit flavonoids reduced the concentration of triglycerides in serum but this response was significant only at the dose of $10 \mathrm{mg} \mathrm{kg}^{-1}$. Other studies also confirm our results. In a study on male adult rats suffering from hyper-lipidemia, treatment with flavonoid-rich extract significantly reduced the triglyserid levels (Zou, Lu 2005). Use of hesperidin (1\%) for 10 days in the diet of the rats that had a diet rich in fat, created a significant decrease in the triglyceride and LDL-cholesterol concentration and significantly increased HDL concentration in plasma (Cha et al., 2001; Zou, Lu 2005).

The present study showed that intraperitoneal injection of C. mas fruit flavonoids for 21 days did not cause any significant reduction in serum LDL concentration. However, in most studies, flavonoid treatment has been found to lower blood LDL. Intraperitoneal use of naringenin for two weeks at a dose of $100 \mathrm{mg} \mathrm{kg}^{-1}$ in mice leads to a significant reduction in the particular types of fat, especially in the LDL plasma (Huong et al. 2006). Using apple polyphenolcontaining capsules for 12 weeks significantly reduced total cholesterol and LDL-cholesterol concentration in healthy subjects (Nagasako-Akazome et al. 2007). Also, the use of flavonoids (quercetin/catechin at ratio of 2:1) at a dose of $8 \mathrm{~g} \mathrm{~kg}^{-1}$ for four weeks caused a significant decrease in the plasma LDL concentration (Nagasako-Akazome et al. 2007). Based on the results of this study, treatment with $C$. mas fruit flavonoidsin increased serum HDL concentration and this increase was significant at the dose of $10 \mathrm{mg} \mathrm{kg}^{-1}$.
This is also in line with the findings of many previous studies. Daily consumption of $250 \mathrm{~mL}$ of cranberry water, which is rich in flavonoids, for four weeks was reported to significantly increase HDL-C concentration (Ruel et al. 2006). Use of flavonoids such as quercetin, morin, naringenin and rutin was also found to increase HDL and 3 -glycerolin concentrations in male rats suffering from hyperlipidemia, which was due to the administration of Triton (300 $\mathrm{mg} \mathrm{kg}^{-1}$ ) (Ruel et al. 2002).

It seems that flavonoids can interact with the synthesis and secretion of lipoproteins rich in triglyceride in liver cells (Wang et al. 2006). Oligomeric proanthocyanidins are capable of inhibiting the activity of pancreatic lipase, which can prevent the digestion of triglycerides (Liu et al. 2013). These compounds can reduce the synthesis and secretion of apolipoprotein B and inhibit cholesterol esterification (Allister et al. 2005). Some flavonoids can reduce the absorption of cholesterol by inhibiting the enzymes involved in the biosynthesis of lipids (Burnett et al. 2011; Bahadoran et al. 2013). Quercetin reduces the amount of fat in mice liver. This effect is probably due to the reduction of oxidative stress levels (Medjakovic et al. 2010). Flavonoid compounds can also reduce the ApoB48 level and downregulate the production of atherogenic chylomicron from intestinal cells and thereby lower plasma triglyceride levels (Pal et al.2005). The ineffectiveness of phenolic compounds found in C. mas fruit in reducing LDL cholesterol is probably due to different types of flavonoids, inadequate levels of these compounds at the administrated doses or the short period of the treatment relative to the previous successful studies. Research has shown that effective doses of flavonoids affect triglycerides and HDL more quickly and easily than they affect LDL (Cha et al. 2001).

In the present study, the used flavonoids were able to decrease rat weight, possibly by reduced digestion and absorption of lipids in the diet, increased fatty acid oxidation and decreased fatty acid synthesis in the liver and degeneration of cells in adipose tissue. Researche has shown that due to on unknown reasons, flavonoids have a better antioxidant effect at lower dosages (Oliviera et al. 2002; Naderi et al. 2006).

Therefore, it seems that treatment with C. mas fruit flavonoids can significantly prevent memory impairment induced by injection of streptozotocin. The results also demonstrated that C. mas fruit flavonoids at the dose of 10 $\mathrm{mg} \mathrm{kg}^{-1}$ can decrease the concentration of serum glucose, triglyceride concentration and rat weight and increase the concentration of serum HDL levels while they did not induce any significant change in serum LDL concentration.

\section{Acknowledgements}

This work was supported by Grants from Arak University (Arak, Iran). 


\section{References}

Abdollahi B., Mesgari Abbasi M., Zakeri Milani P., Nourdadgar A., Banan Khojasteh M., Nejati V. 2014. Hydro-methanolic extract of Cornus mas L. and blood glucose, lipid profile and hematological parameters of male rats. Iranian Red Crescent Med. J. 16: e17784.

Alavian S.M., Banihabib N., Es Haghi M., Panahi F. 2014. Protective effect of Cornus mas fruits extract on serum biomarkers in $\mathrm{CCl}_{4}$-induced hepatotoxicity in male rats. Hepatitis Monthly 14: 10330 .

Allister E.M., Borradaile N.M., Edwards J.Y., Huff M.W. 2005. Inhibition of microsomal triglyceride transfer protein expression and apolipoprotein B100 secretion by the citrus flavonoid naringenin and by insulin involves activation of the mitogen-activated protein kinase pathway in hepatocytes. Diabetes 54: 1676-163.

Bahadoran Z., Mirmiran P., Azizi F. 2013. Dietary polyphenols as potential nutraceuticals in management of diabetes. J. Diabetes Metab. Disord. 12: 43.

Burnett B.P., Bitto A., Altavilla D., Squadrito F., Levy R.L., Pillai L. 2011. Flavocoxid inhibits phospholipase A2, peroxidase moieties of the cyclooxygenases (COX), and 5-lipoxygenase, modifies $C O X-2$ gene expression, and acts as an antioxidant. Mediators of Inflammation Article ID 385780, 11 pages.

Cha J.Y., Cho Y.S., Kim I., Anno T., Rahman S.M., Yanagita T. 2001. Effect of hesperetin, a citrus flavonoid, on the liver triacylglycerol content and phosphatidate phosphohydrolase activity in orotic acid-fed rats. Plant Foods Hum. Nutr. 56: 349-358.

Choi Y.J., Kang J.S., Park J.H., Lee Y.J., Choi J.S., Kang Y.H. 2003. Polyphenolic flavonoids differ in their antiapoptotic efficacy in hydrogen peroxide-treated human vascular endothelial cells. J. Nutr. 133: 985-991.

Chu W.Z., Qian C.Y. 2005. Expressions of Abeta1-40, Abeta1-42, tau202, tau396 and tau404 after intracerebroventricular injection of streptozotocin in rats. Academic Journal of the First Medical College of PLA 25: 168-170. [in Chinese]

De S.E., Zanatta L., Seifriz I., Creczynski-Pasa T.B., Pizzolatti M.G., Szpoganicz B. 2004. Hypoglycemic effect and antioxidant potential of kaempferol-3,7-O-(alpha)-dirhamnoside from Bauhinia forficata leaves. J. Nat. Prod. 67:829-32.

Drapeau E., Mayo W., Aurousseau C., Moal M.L., Piazza V.P., Abrous D.N. 2003. Spatial memory performances of aged rats in the water maze predict levels of hippocampal neurogenesis. Proc. Natl. Acad. Sci.USA 100: 14385-14390.

Ebrahimi-Mamaghani M., Arefhosseini S.R., Golzarand M., Asgarzadeh A.A., Vahed-Jabbary M. 2009. Long-term effects of processed Berberis vulgaris on some metabolic syndrome components. Iran. J. Endocrinol. Metab. 11: 41-47.

Eshaghi M., Zare S., Banihabib N., Nejati V., Farokhi F., Mikaili P. 2012. Cardioprotective effect of Cornus mas fruit extract against carbon tetrachloride induced-cardiotoxicity in albino rats. J. Basic. Appl. Sci. Res. 2: 11106-11114.

Ejaz Ahmed M., Khan M.M., Javed, H., Vaibhav, K., Khan, A., Tabassum R., Ashafaq M., Islam F., Safhi M.M., Islam F. 2013. Amelioration of cognitive impairment and neurodegeneration by catechin hydrate in rat model of streptozotocin-induced experimental dementia of Alzheimer's type. Neurochem. Int. 62: 492-501.

Fallahi F., Roghani M., Moghadami S. 2012. Citrus flavonoid naringenin improves aortic reactivity in streptozotocin- diabetic rats. Indian J. Pharmacol. 44: 382-386.

Frémont L., Gozzélino M.T., Franchi M.P., Linard A. 1998. Dietary flavonoids reduce lipid peroxidation in rats fed polyunsaturated or monounsaturated fat diets. J. Nutr. 128: 1495-1502.

Gould E., Reeves A.J., Graziano M.S., Gross C.G. 1999. Neurogenesis in the neocortex of adult primates. Science 286: 548-552.

Harborne J., Williams A. 2000. Advances in flavonoid research since. Phytochemistry 55: 481-504.

Haroutunian V., Hoffman L.B., Beri M.S. 2009. Is there a neuropathology difference between mild cognitive impairment and dementia? Dialogus Clin. Neurosci. 11: 171179.

Heo H.J., Kim D.O., Shin S.C., Kim M.J., Kim B.G., Shin D.H. 2004. Effect of antioxidant flavanone, naringenin, from Citrus junoson neuroprotection. J. Agric. Food Chem. 52: 1520-1525.

Hoseini S.M., Nobakht M. 2012. Study of histopathological lesions in CA1 of the hippocampus after injection of beta-amyloid in a rat model of Alzheimer's disease. J. Babol. Univ. Med. Sci. 14: 90-96.

Huong D.T., Takahashi Y., Ide T. 2006. Activity and mRNA levels of enzymes involved in hepatic fatty acid oxidation in mice fed citrus flavonoids. Nutrition 22: 546-552.

Iosa J.A., Cisternasa P., Arresea M., Barjac S., Inestrosaa N.C. 2014. Is Alzheimer's disease related to metabolic syndrome? A Wnt signaling conundrum. Prog. Neurobiol. 121: 125-146.

Jeremy P. 2007. The interactions of flavonoids within neuronal signalling pathways. Genes Nutr. 2: 257-273.

Kamalakkannan N., Prince P.S. 2006. Antihyperglycaemic and antioxidant effect of rutin, a polyphenolic flavonoid, in streptozotocin-induced diabetic wistar rats. Basic Clin. Pharmacol Toxicol. 98: 97-103.

Kaneto H., Kajimoto Y., Miyagawa J., Matsuoka T., Fujitani Y., Umayahara Y., Hanafusa T., Matsuzawa Y., Yamasaki Y., Hori M. 1999. Beneficial effects of antioxidants in diabetes possible protection of pancreatic b-cells against glucose toxicity. Diabetes 48: 2398-406.

Kundurovic Z., Hasanagic S., Bilalovic N., Gavrankapetanovic F., Alicelebic S. 2009. Pro-apoptotic protein Bax and antiapoptotic protein Bcl-2 expression in streptozotocin model of Alzheimer's disease. Health Med. 3: 520.

Lei C., Ting H., Yi H., Ji-Zhong S., Si J., Man-Wen J. 2011. Pentamethylquercetin improves adiponectin expression in differentiated 3T3-L1 cells via a mechanism that implicates PPAR $\gamma$ together with TNF- $\alpha$ and IL-6. Molecules 16: 57545768.

Liu S., Li D., Huang B., Chen Y., Lu X., Wang Y. 2013. Inhibition of pancreatic lipase, $\alpha$-glucosidase, $\alpha$-amylase, and hypolipidemic effects of the total flavonoids from Nelumbo nucifera leaves. J. Ethnopharmacol. 149: 263-269.

Markham K.R. 1982. Techniques of Flavonoid Identification. Academic Press, pp. 16-55.

Medjakovic S., Monika Mueller M., Jungbauer A. 2010. Potential health-modulating effects of isoflavones and metabolites via activation of PPAR and AhR. Nutrients 2: 241-279.

Mehla J., Pahuja M., Gupta Y.K. 2013. Streptozotocin-induced sporadic Alzheimer's disease: selection of appropriate dose. J. Alzheimers Dis. 33: 17-21.

Michalik L., Auwerx J., Berger J.P., Chatterjee V.K., Glass C.K., Gonzalez F.J., Grimaldi P.A., Kadowaki T., Lazar M.A., O'Rahilly S. 2006. International Union of Pharmacology. LXI. 
Peroxisome proliferator-activated receptors. Pharmacol Rev. 58: 726-741.

Mozaffarian V. 2005. Trees and shrubs of Iran. Farhang Moaser Press. Tehran.

Naderi G.A., Asgari S., Movahedian A., Sabet B., Shirvani H. 2006. Anti-oxidant effects of some natural pure flavonoids on susceptibility of LDL to oxidation. J. Isfahan Univ. Med. Sci. 22: 57-62.

Nagasako-Akazome Y., Kanda T., Ohtake Y., Shimasaki H., Kobayashi T. 2007. Apple polyphenols influence cholesterol etabolism in healthy subjects with relatively high body mas index. J. Oleo Sci. 56: 417-428.

Narimani-Rad M., Lotfi A., Mesgari Abbasi M., Abdollahi B. 2013. The effect of Cornelian Cherry (Cornus mas L.) rxtract on serum ghrelin and corticosterone levels in rat model. J. Pharm. Biomed. Sci. 3: 7-9.

Oliviera T.T., Gomes S.M., Najem T.J., Costa N.M.B., Secom P.R. 2002. Effect of different doses of flavonoids on hyperlipidemic rats. Rev. Nutr. 15: 45-51.

Pal S., Ho S.S., Takechi R. 2005. Red wine polyphenolics suppress the secretion of ApoB48 from human intestinal CaCo-2 cells. J. Agric. Food Chem. 53: 2767-2772.

Paxinos G., Watson C. 1998. The Rat Brain in Stereotaxic. $4^{\text {th }}$ ed. Academic Press, San Diago.

Rai S., Kamat P.K., Nath C., Shukla R. 2013. A study on neuroinflammation and NMDA receptor function in STZ (ICV) induced memory impaired rats. J. Neuroimmunol. 15: $1-9$.

Razay G., Vreugdenhil A., Wilcock G. 2007. The metabolic syndrome and Alzheimer disease. Arch. Neurol. 64: 93-96.

Rendeiro C., Guerreiro J.D., Williams C.M., Spencer J.P. 2012. Flavonoids as modulators of memory and learning: molecular interactions resulting in behavioural effects. Proc. Nutr. Soc. 71: 246-262.

Roghani M., Baluchnejadmojarad T., Khalili M. 2007. The effect of chronic oral administration of Withania somnifera root on learning and memory in diabetic rat's using passive avoidance test. Sci. J. Hamadan Univ. Med. Sci. 13: 10-17.

Roghani M., Joghataiee M.T., Jalali M.R., Baluchnejadmojarad T. 2006. Time course of change in passive avoidance and Y-maze performance in male diabetic rats. Iran. Biomed. J. 2: 99-104.

Ruderman N., Chisholm D., Pi-Sunyer X., Schneider S. 1998. The metabolically obese, normal-weight individual revisited. Diabetes 47: 699-713.

Ruel G., Pomerleau S., Couture P., Lemieux S., Lamarche B., Couillard C.H. 2006. Favourable impact of low-calorie cranberry juice consumption on plasma HDL-cholesterol concentrations in men. British J. Nutr. 96: 357-364.

Shors, T.J., Townsend, D.A., Zhao, M., Kozorovitskiy, Y., Gould, E., 2002. Neurogenesis may relate to some but not all types of hippocampal-dependent learning. Hippocampus 12: 578-584.

Shukitt-Hale B., Lau F.C., Carey A.N., Galli R.L., Spangler E.L., Ingram D.K. 2008. Blueberry polyphenols attenuate kainic acid-induced decrements incognition and alter inflammatory gene expression in rat hippocampus. Nutr. Neurosci. 11: 172182.

Somi M.H., Banihabib N., Dehghan G.R., Haghi M., Panahi F. 2014. Hepatoprotective effect of Cornus mas fruits extract against carbon tetrachloride-induced hepatic damage in male albino rats. Thrita 3: 17625 .

Spencer J.P. 2009. The impact of flavonoids on memory: physiological and molecular considerations. Chem. Soc. Rev. 38: 1152-1161.

Sun M.K., Hongpaisan J., Alkon D.L. 2009. Postischemic PKC activation rescues retrograde and anterogradelong-term memory. Proc. Natl. Acad. Sci. USA 106: 14676-14680.

Szkudelski T., Szkudelski K. 2011. Anti-diabetic effects of resveratrol. Ann. N.Y. Acad. Sci. 1215: 34-39.

Tanaka S., Togashi K., Rankinen T., Perusse L., Leon A.S., Rao D.C. 2002. Is adiposity at normal body weight relevant for cardiovascular disease risk? Int. J. Obes. Relat. Metab. Disord. 26: $176-183$.

Vanhanen M., Koivisto K., Moilanen L., Helkala E.L., Hänninen T., Soininen H., Kervinen K., Kesäniemi Y.A., Laakso M., Kuusisto J. 2006. Association of metabolic syndrome with Alzheimer disease. A population-based study. Neurology 67: 843-847.

Wang S., Noh S.K., Koo S.I. 2006. Green tea catechins inhibit pancreatic phospholipase $\mathrm{A}(2)$ and intestinal absorption oflipids in ovariectomized rats. J. Nutr. Biochem. 17: 492-498.

Wein S., Behm N., Petersen R.K., Kristiansen K., Wolffram S. 2010. Quercetin enhances adiponectin secretion by a PPAR-gamma independent mechanism. Eur. J. Pharm. Sci. 41: 16-22.

Williamson G., Clifford M.N. 2010. Colonic metabolitesof berry polyphenols: the missing link to biological activity? British J. Nutr. 104: 48-66.

Zhi-you C.A.I., Yong Y.A.N. 2007. Pathway and mechanism of oxidative stress in Alzheimer's disease. J. Medic. Coll. PLA 22: 320-324.

Zou Y., Lu Y., Wei D. 2005. Hypocholesterolemic effects of a flavonoid-rich extract of Hypericum perforatum L. in rats fed a cholesterol-rich diet. J. Agric. Food Chem. 53: 2462-2466. 